\title{
0 Imperialismo do Brasil na Bacia do Prata
}

MárioMaestri ${ }^{*}$

Em 1979, J. J. Chiavenato publicou reportagem jornalística de viés populista e anti-imperialista sobre a Guerra do Paraguai. Esse trabalho de divulgação histórica, de enorme sucesso, apoiava-se em temas da historiografia revisionista platina ignorados no Brasil (CHIAVENATO, 1986). O autor abraçava a tese de que a guerra era desejada pela Inglaterra, muito questionada no Prata (PEÑA, 1975, p. 61).

Em 1985, sem despertar maior discussão, Luiz Alberto Moniz Bandeira publicou, por pequena editora, $O$ expansionismo brasileiro: o papel do Brasil na Bacia do Rio da Prata. $\mathrm{Da}$ colonização ao Império. O livro continha "apresentação" do autor assinada em fins de 1981 (BANDEIRA, 1985). No livro, o autor deu ampla abordagem à Guerra do Paraguai, embora o título do trabalho não conduzisse a essa percepção.

O livro era prefaciado pelo embaixador Teixeira Soares, estudioso das relações internacionais, não antipático ao expansionismo criticado pelo autor. Assinava a orelha Enio Silveira, proprietário da Civilização Brasileira, que publicara livros de Bandeira e sofrera retaliações da ditadura (BANDEIRA, 1985, p. 13-16). O trabalho foi reapresentado dez anos mais tarde, dessa vez com referência ao Paraguai e à guerra no título, pela Editora da UnB e pela editora Ensaios, com uma reedição (BANDEIRA, 1995).

Tese de doutoramento defendida na USP em fins dos anos 1970, o estudo constituía marco na historiografia brasileira das relações do Império com as nações do Prata e das razões da Guerra da Tríplice Aliança. Era o primeiro trabalho revisionista erudito no Brasil, e seu teor superava as explicações nacional-patrióticas sobre as origens do conflito.

Moniz Bandeira defendia, como tese central, o caráter colonialista e imperialista do Império naquela região, razão essencial da agressão ao Uruguai, em 1864, e ao Paraguai, em 1865-70, em aliança com a Argentina unitária e com o Uruguai florista. Tudo para impor sua hegemonia.

\footnotetext{
Professor do Programa de Pós-Graduação em História da Universidade de Passo Fundo. Doutor em Ciências Históricas pelo Université Catholique de Louvin, UCL, Bélgica. Pós-Doutor em História pelo Université Catholique de Louvin, UCL, Bélgica.
}

Recebido em: 01/08/2013 Aprovado em: 05/09/2013 http://dx.doi.org/10.5335/hdtv.14n.1.3806 
Esse trabalho referencial foi e segue sendo destacado pela negação da tese de guerra querida pela Inglaterra, questão de importância marginal, já impugnada no estudo pela apresentação dos complexos conflitos platinos e do impulso imperialista-colonialista imperial. Raros trabalhos retomaram e ampliaram essa sensível leitura.

A escassa repercussão inicial relativa do trabalho não se deveu a ser o autor desconhecido e o livro lançado por editora de pouco alcance. Em 1985, Muniz Bandeira era já autor de dois títulos historiográficos de amplo sucesso.

\section{A trajetória do autor}

Muniz Bandeira nasceu em Salvador, na Bahia, em 1935, mudando-se jovem para o RJ, onde se formou em Direito. Em 1961, com outros intelectuais marxistas - Rui Mauro Marini, Octávio Ianni, Paul Singer, etc. -, fundou a Organização Revolucionária Marxista - Política Operária (Polop), pequena organização leninista, luxemburguista e trotskista.

A Polop opunha-se ao colaboracionismo pecebista e avançava programa socialista para o Brasil, defendido por Muniz Bandeira em O Caminho da Revolução Brasileira (1962). Entre outros ensaios, ele publicara, no Brasil e em Havana, o livro de poesia Ode a Cuba (BANDEIRA, 1963).

Após o golpe de 1964, Moniz Bandeira refugiou-se no Uruguai e, em 1965, voltou ao Brasil, tendo sido preso em 1969 e 1973. Em 1967, publicou, em parceria, $O$ ano vermelho: a Revolução Russa e seus reflexos no Brasil, de ampla recepção, reapresentado em 1980 (BANDEIRA; MELO; ANDRADE, 1967). Em 1973, preso, lançou Presença dos Estados Unidos no Brasil: dois séculos de história, obra também de grande repercussão (BANDEIRA, 1973).

Com bolsa da Fundação Ford e de outros centros financiadores, preparou sua tese de doutoramento. Quando da redemocratização controlada, participou da fundação do PDT e da primeira administração brizolista do RJ, sem abandonar o ensino universitário e a historiografia. Aposentado, radicou-se na Alemanha, em 1996, prosseguindo sua investigação sobre as relações internacionais do Brasil e a história contemporânea.

\section{Nova edição, novo título}

Quatorze anos após a terceira reapresentação, esse clássico historiográfico conhece nova edição, revista e ampliada, com caderno de ilustrações, publicada pela Civilização Brasileira, com modificação no título - A expansão do Brasil e a formação dos Estados na Bacia do Prata: Argentina, Uruguai e Paraguai. Da colonização à Guerra da Tríplice Aliança (BANDEIRA, 2012).

O livro contém prefácio de Teixeira Soares à primeira edição; "Prólogo" assinado por J. C. H. Krauer; e prefácio do autor quando da segunda edição, além de uma também sua - breve nota de apresentação, na qual são também expostas as razões não muito óbvias para a modificação do título, de "expansionismo" para "expansão". Traz, ainda, breve apêndice, intitulado de "D. João VI e a construção do Estado brasileiro".

Com ampliações dos argumentos, notas e bibliografia, o livro mantém a estrutu- 
ra e o desenvolvimento da primeira edição, com onze capítulos e conclusão. Em três breves capítulos iniciais, defende-se o impulso expansionista lusitano em direção ao Prata, na procura da conquista de Buenos Aires, desde os inícios da colonização, antecedente de empreendimentos semelhantes após 1808 e 1822. A introdução enriquece a discussão, ainda que fusione objetivos e causas comumente diversos daqueles movimentos, nos seus mais de três séculos.

Na quarta edição, não se atualizou a bibliografia que apoiou a apresentação geral do quadro introdutório, apesar da superação de muitos trabalhos utilizados pela expansão das investigações. Uma atualização que permitiria sanar não poucos hiatos sobre a ação dos bandeirantes, a estrutura das missões, a organização das sociedades aldeãs guaranis, a ocupação e organização do extremo-sul do Brasil, etc. (BANDEIRA, 2012, p. 39 et seq.).

\section{0 vencedor de Monte Caseros}

Nos três capítulos seguintes, aborda-se a crise da independência no Prata, o projeto joanino de fundação de Império no sul da América, a insurreição artiguista e a invasão e ocupação luso-brasileira da Banda Oriental. Na discussão da gênese do Uruguai independente, destaca-se a herança maldita que constitui o domínio do norte do país por criadores escravistas sulinos, dependentes da livre transferência dos gados para as charqueadas do RS.

$\mathrm{O}$ autor analisa a crise e as contradições das províncias do vice-reinado do Prata, após a Revolução de Maio (1810). Destaca a luta das classes mercantis portenhas para a restauração do monopólio de que gozara e a oposição provincial à restauração de submissão semicolonial. Como habitual na historiografia platina, vê a oposição provincial a Buenos Aires como resistência pré-capitalista à penetração capitalista, ainda que a hegemonia do capital mercantil portenho não ensejasse produção capitalista autóctone, consolidando as estruturas pré-capitalistas e semicoloniais (MAESTRI, 2012).

Moniz Bandeira serve-se da discussão acerca da ascensão e queda de Rosas para apresentar sensivelmente as razões profundas das dissensões do Prata. Para tal, apoia-se em rica revisão de autores, sobretudo platinos, que continuam sendo, ainda em boa parte, semidesconhecidos da historiografia brasileira - Blas Garay, Carlos Pastore, J. A. Ramos, José Pedro Barrán, J. B. Alberdi, Lucia Sala Touron, Sanchez Quell, etc. Utiliza o magnífico trabalho de Raul de Andrada e Silva sobre o Paraguai francista, semiolvidado pela historiografia brasileira (ANDRADA; SILVA, 1978).

Aponta a queda de Rosas (1852) como primeiro momento conclusivo da construção da hegemonia do Império no Prata e o defenestramento do senhor portenho para o qual o governo imperial aproximara-se do Paraguai e apoiara a dissidência de J. J. de Urquiza, chefe federalista da província de Entre Ríos.

Detalha a redução do Uruguai à situação de semiprotetorado após a derrota de Rosas e refere-se ao fracasso da expedição naval imperial, em 1854-5, contra o Paraguai, para liberação plena da navegação no rio homônimo e concessões na demarcação das regiões fronteiriças, ricas em ervais (TEIXEIRA, 2012). 


\section{Estado Imperialista}

A partir da visão gramsciana de hegemonia, Bandeira (2012) define o Império do Brasil como a então única nação sul-americana com vontade e condições de projetar a "vontade social de suas classes dominantes" sobre os vizinhos, através da "guerra vitoriosa", que, não raro, dispensava o combate. Lembra que o Império não procurara equilíbrio, mas impor sua hegemonia no Prata (BANDEIRA, 2012, p. 199 et seq.).

O autor define a ação do Império como "imperialista", no sentido proposto por Lenin, não ao referir-se às nações capitalistas industrializadas e ao capital financeiro, mas ao qualificar a ação de poderosos Estados, mesmo anteriores ao advento do capitalismo, como Roma, que também se apoiava na escravatura.

Na expansão hegemônica lusitana, luso-brasileira e imperial, ele enfatiza a impulsão mercantilista para o controle das grandes vias comerciais e dos mercados - visão de cunho circulacionista que privilegia o comércio em detrimento da produção - e aborda, sem maior detença, as dinâmicas socioprodutivas estruturais. Vê no "mercantilismo" a "principal força propulsora da conquista de territórios" (BANDEIRA, 2012, p. 75).

Mesmo se referindo à categoria modo de produção, Bandeira não avança, no relativo ao Brasil, além do registro de "modo de produção assentado no trabalho escravo", na "exploração extensiva da terra", no latifúndio e no mercantilismo (2012, p. 75). Tal leitura superestima o interesse lusitano no domínio dos tributários do Rio da Prata, antes da potenciação da navegação pelos barcos a vapor.
O autor propõe que o Estado imperial seria continuidade sem rupturas do Estado lusitano. Abraçando a tese tradicional, apresenta a independência como obra nascida da transferência da família real e da ação clarividente joanina, concluída por Pedro I. Não vislumbra a unidade nacional, em torno de monarquia centralista e autoritária, como defesa da escravidão.

Definição mais precisa da formação escravista enriqueceria a compreensão do caráter imperialista do Estado brasileiro e de seu posterior retrocesso. O fim da Guerra do Paraguai como cerre de "ciclo histórico" na evolução do "Estado brasileiro", verdadeiro "ápice de sua política colonial e imperialista" no Prata, constitui importante constatação conclusiva do autor, nesse trabalho fundamental (BANDEIRA, 2012, p. 257).

Após o final da Guerra da Tríplice Aliança, a hegemonia, sobretudo política, do Império no Prata seria deslocada pelo imperialismo essencialmente econômico de "algumas poucas potências imperialistas industrializadas", devido ao handicap negativo posto pela produção, pelas relações escravistas e pelo atraso na industrialização que determinaram. A escravidão, que fora vetor de potência e unidade ao Estado imperial, passou a ser razão de sua fragilidade e atraso (BANDEIRA, 2012, p. 257).

A ampla análise da documentação diplomática nos arquivos argentinos, brasileiros, estadunidenses, ingleses, paraguaios, etc. é outro ponto alto do trabalho. Jamais a historiografia brasileira discutira a ação do Império no Prata, em forma sintética e sistemática, a partir de tão ricas fontes. Riqueza e ênfase documental diplomática que talvez 
tenham contribuído para uma discussão menos ampla das bases materiais e sociais das formações americanas.

\section{Lopizmo negativo, lopizmo positivo}

Os dois capítulos conclusivos são dedicados, em boa medida, às razões do conflito entre o Paraguai e o Império, no contexto da procura da extensão e do uso da hegemonia que a segunda nação gozava. Moniz Bandeira destaca, pertinentemente, a importância da disputa pelo Império dos ervais do atual Mato Grosso e propõe que cabiam, em grande parte, ao Paraguai.

Realiza-se esboço aproximativo da formação paraguaia que abraça, algumas vezes, propostas caricaturais positivas e negativas daquela realidade - regime estatal restringido ao déspota e economia e sociedade determinadas por ele; superarmamento, militarização e população paraguaia, etc. (BANDEIRA, 2012, p. 227 et seq.).

A partir, não raro, de legendas históricas, mantém-se a desqualificação original de Solano López definido como militar, diplomata e político inepto e vaidoso, buscando intervir no Prata para se transformar em imperador. Mesmo obliquamente, sugere-se que foi o responsável pelo conflito, proposta apologética da Tríplice Aliança, retomada pela historiografia nacional-patriótica.

Em referências conclusivas a questões já fora dos objetivos do trabalho, elide-se explicação, mesmo sumária, por além das legendas, da inesperada duração da guerra, motivada pela resistência da população camponesa à invasão aliancista e pela incapacidade do Estado pré-nacional imperial - avaliada positivamente pelo autor - de enfrentar conflito de tal dimensão.

Por além do papel desempenhado por Solano López, a visão positiva ou negativa de sua determinação demiúrgica do confronto encobre as determinações profundas que levaram ao conflito e o embalaram. Determinações sobre as origens reais daquele embate que Moniz Bandeira iluminou de forma magistral e pioneira, em 1985, no que se refere à historiografia brasileira.

\section{Referências}

ANDRADA E SILVA, R. Ensaio sobre a Ditadura do Paraguai: [1814-1840]. São Paulo, 1978.

BANDEIRA, L. A. M. O caminho da Revolução Brasileira. Rio de Janeiro: Melso, 1963.

. Presença dos Estados Unidos no Brasil: dois séculos de História. Rio de Janeiro: Civilização Brasileira, 1973.

O expansionismo brasileiro: o papel do Brasil na Bacia do Prata. Da colonização ao Império. Rio de Janeiro: Philobiblion, 1985.

O expansionismo brasileiro e a formação dos Estados na Bacia do Prata: Argentina, Uruguai e Paraguai. Da colonização à Guerra da Tríplice Aliança. 2. ed. São Paulo: Ensaios; Brasília: Ed. UnB, 1995.

A expansão do Brasil e a formação dos Estados na bacia do Prata: Argentina, Uruguai e Paraguai. Da colonização à Guerra da Tríplice Aliança. 4. ed. Rio de Janeiro: Civilização Brasileira, 2012.

BANDEIRA, L. A. M.; MELO, C.; ANDRADE, A. T. O ano vermelho: a Revolução Russa e seus reflexos no Brasil. Rio de Janeiro: Civilização Brasileira, 1967. 
CHIAVENATO, J. J. Genocídio americano: a Guerra do Paraguay. São Paulo: Brasiliense, 1986.

MAESTRI, M. Círculo de Ferro. Milcíades Peña e o capitalismo pastoril argentino. Socialismo $O$ Barbárie, Buenos Aires, 2012. Disponível em: <http:/ / www.socialismo-o-barbarie.org/historias/100620_milciadespenia.htm>. Acesso em: 14 jan. 2013.

PEÑA, M. La era de Mitre: de Caseros a la Guerra de la Triple Infamia. 3. ed. Buenos Aires: Fichas, 1975.

TEIXEIRA, F. B. A primeira Guerra do Paraguai: a expedição naval imperial ao Paraguai de 1854-1855. Passo Fundo: Méritos, 2012. 